\title{
Incorporation of Fluconazole and Ocimum Sanctum Oil in Soft Denture Liners to Treat Biofilms of Candida albicans Associated with Denture Stomatitis
}

\author{
Aamir Zahid Godil 1*, Diksha Bhagat 2, Parijat Das ${ }^{3}$, Arshi llyas Kazi ${ }^{1}$, Ramandeep Dugal ${ }^{1}$, \\ Surekha Satpute ${ }^{2^{*}}$ \\ ${ }^{1}$ Department of Prosthodontics, M. A. Rangoonwala College of Dental Sciences and Research Centre, Maharashtra, India \\ ${ }^{2}$ Department of Microbiology, Savitribai Phule Pune University, India \\ ${ }^{3}$ Department of Biosciences and Bioengineering, Savitribai Phule Pune University, India
}

\section{Abstract}

Purpose: To investigate the In Vitro activity of incorporated antifungal agents like Fluconazole and Ocimum sanctum oil (Tulsi) in the denture soft liners to reduce the risks associated with the biofilms of Candida albicans.

Materials and Methods: In the current study, the minimum inhibitory concentration (MIC) of two antifungal agents namely Fluconazole and $O$. sanctum (Tulsi oil) against $C$. albicans (ATCC 10231) was evaluated to examine their effect in reducing the count of candida and its biofilms. Analysis of physical properties such as surface roughness and hardness of soft denture liners (test and control) were also performed. The effect of both antifungal agents was also observed on cell morphology of candida cells using scanning electron microscopy (SEM).

Results: Studies confirmed MIC value for fluconazole and $O$. sanctum oil as 600 and 400 $\mu \mathrm{g} / \mathrm{ml}$ respectively. Surface hardness and roughness of soft denture material (test) remained unaltered. Finally, SEM studies also proved the effectiveness of incorporated antifungal agents on the cell morphology of $C$. albicans at their respective MIC values.

Conclusions: This approach allows the prolonged drug release in the oral cavity which simultaneously treats the injured denture bearing tissues and also the infection, biofilms of candida without compromising on their physical properties. These studies are significant and have tremendous medicinal and therapeutic relevance.

Keywords: Antifungal Agents; Biofilms; Candida; Scanning Electron Microscope; Soft Liners; Hardness; Surface Roughness; Minimal Inhibitory Concentration; Denture Stomatitis.

Citation: Godil A, et al. (2021) Incorporation of Fluconazole and Ocimum Sanctum Oil in Soft Denture Liners to Treat Biofilms of Candida albicans Associated with Denture Stomatitis. Dentistry 3000. 1:a001 doi:10.5195/d3000.2021.120 Received: October 29, 2020 Accepted: December 16, 2020 Published: February 5, 2021

Copyright: (C2021 Godil A, et al. This is an open access article licensed under a Creative Commons Attribution Work 4.0 United States License.

Email: ramandeepdugal@gmail.com

\section{Introduction}

Denture soft liners are widely used for restoring the health of abused or inflamed tissues in the oral cavity which is brought about by the hard denture materials by providing cushioning and evenly distributing the load on the oral tissues during mouth movements. However, these liners surface harbor and support the adhesion, colonization of several microbes, especially pathogens like Candida albicans that result in lesion formation in denture wearers [1]. This microbial colonization on denture surface represented as a biofilm of microbial communities which are consistently encased within an extracellular polysaccharide matrix produced by the organisms themselves. Candida strains are proficient in forming biofilms and this has been linked to both increased expression of virulence factors and also lesser susceptibility to antimicrobial agents $[2,3]$. Biofilms permits the persistence as well as resistance to several antifungals agents and further affect the strategies in preventing, treating 
infections instigated by candida sp [4].

Biofilm related infections are efficiently tackled by incorporating powerful antimicrobial agents in denture soft liners. Several investigators have advocated the usage of antibiotics, few medicinal oils in treating candida infections [5]. An ideal antimicrobial agent should have good stability, high efficiency, broad spectrum, long-lasting antimicrobial activity and biocompatibility, rendering them useful for biomedical applications $[5,6]$. Numerous antifungal drugs, antiseptic solutions, chitosan salts, metallic oxides, surface coatings' etc. have been proposed in literature [7-10]. Fluconazole, one of the most popular antifungal agents has been witnessed from the literature. Fluconazole basically contains a triazole ring instead of an imidazole ring and it has a lower molecular weight (306.271 g/mol) making it more water soluble as compared to other azole compounds. It has a high bioavailability (92\%) when administered intra-orally $[11,12]$. The antifungal activities of medicinal herb oils like Origanum oil, and numerous other essential oils have been documented [1317]. Sparse literature suggest the use of Tulsi - O. sanctum oil incorporated in soft liners. Gupta et al demonstrated the use of $O$. sanctum in combination with chlorhexidine (skin - disinfectant, antiseptic) for mouthwash preparation against dental plaque and gingival inflammation [17]. Shokeen et al have proposed the presence of eugenol component from $O$. sanctum for its medicinal potential against multi drug resistant (MDR) and susceptible strains $[18,19]$. Even though the potential of various plant extracts or essential oils is known, it is important to highlight that the literature on the usage of such extracts in prosthodontics is inadequate. We wish to state a noteworthy observation here that in comparison with other plant extracts, $O$. sanctum oil has not been exploited thoroughly for prosthodontics purposes.

Incorporation of antifungal medicaments or additives, in any form is likely to modify or compromise the physical and mechanical properties of soft liners. It is therefore important that only the minimum inhibitory concentration (MIC) of the medicament can be incorporated to ensure minimum changes in the properties of these materials. Many researchers have studied the effect of incorporated antifungal medicaments on the properties of soft liners such as dimensional stability, surface roughness, hardness, tensile strength, water sorption, modulus of elasticity, and weight in soft liner materials [5,13,19-23].

Among the several properties evaluated, surface roughness is the most critical one, since; rougher surfaces have a greater affinity to biofilm formation, and thus favor the emergence/maintenance of oral pathologies. Release of alcohol and plasticizers from these soft lining materials to the liquid medium also result in increased roughness. The fine pores created by the rough surfaces act as an attachment point as well as breeding ground for the microbes, initiating the process of biofilm formation [24]. Hardness is another such property which is regarded as a fundamental one since it represents a simple method to determine its modulus of elasticity. The greater the content of plasticizers in the material, the softer it becomes. In this context, a major disadvantage of soft lining materials is the rapid loss of plasticizer that leads the gradual hardening and even oral discomfort to the user [24].

The purpose of our present study was to evaluate In Vitro antifungal activity of fluconazole and $O$. sanctum seed oil incorporated in a soft liner. We also investigated the effect of these inclusions on the hardness and surface roughness of the soft liner. Lastly, Scanning Electron Microscopy (SEM) analysis was also carried out to demonstrate the effect of antifungal agents on the morphology of $C$. albicans. The null hypothesis of this study is that there is no difference in the outcomes of physical properties of denture soft liners due to the incorporation of the two test antifungal agents.

\section{Material and Methods}


entistrப $3 \square \square \square$

Vol 9 No 1 (2021) DOI 10.5195/d3000.2021.120

\section{Culture and growth conditions}

Culture of Candida albicans (ATCC 10231) was obtained from Swami Ramanand Teerth Marathwada University - SRTMU, Nanded, Maharashtra, India Fungal culture was grown in sterile Yeast Malt Broth (YMB, HiMedia, India) overnight at $30^{\circ} \mathrm{C}$ under shaking conditions. Figure 1a represents well isolated, off-white coloured, circular, regular edged colonies of candida sp. grown on Yeast Malt Agar plates (YMA, HiMedia, India). Morphological features of $C$. albicans were evaluated for freshly grown 24 hours old culture on a trinocular microscope (AxioCam ERc5s: Zeiss, Germany) under 10x magnification after staining with lactophenol cotton blue stain (HiMedia, India) (Figure 1b). The fungal morphology was analysed on a computer screen using Zen lite 2011 software (Zeiss Microscopy, Germany) to observe oval, budding yeast like cells and confirm its active growth.

Determination of Minimum Inhibitory Concentration (MIC) of antifungal agents by agar well diffusion assay

Agar well diffusion technique was performed to evaluate the MIC of the antifungal agents: Fluconazole (150 mg tablet: Fluka, Cipla- Uttarakhand, India), and Ocimum sanctum (P. H. Gandhi Chemicals, Pune, Maharashtra, India) against the fungal strain C. albicans (ATCC 10231). The turbidity of overnight
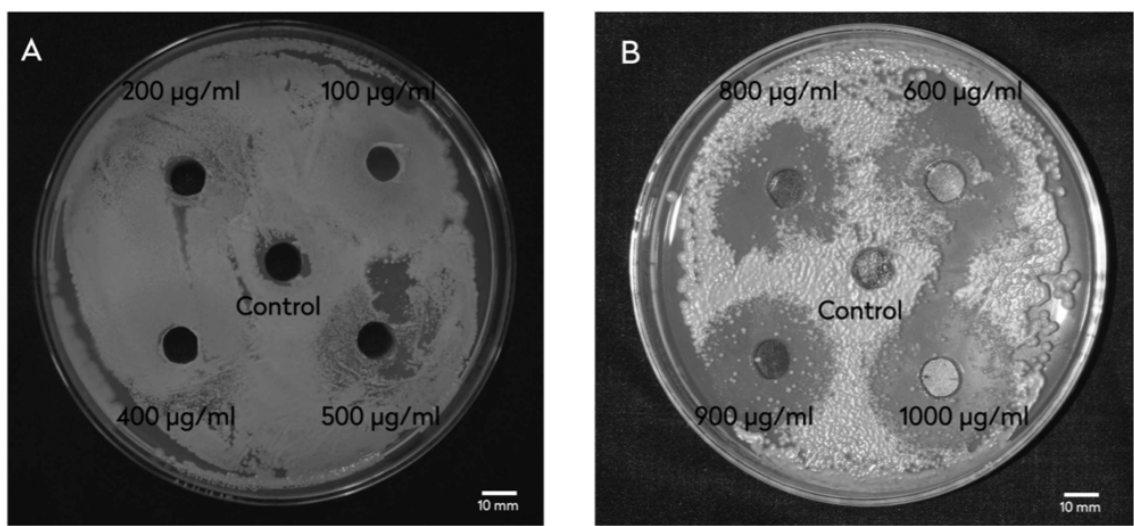

Figure 1. A) Colony characteristics of C. albicans grown on Yeast Malt Agar plates, B) Microscopic image (10x) of $C$. albicans stained with lactophenol cotton blue

freshly grown fungal culture was adjusted to a cell count of $1 \times 10^{5}$ cells/ml and further $100 \mu$ of the culture was uniformly spread over YMA plates. Wells were dug into the agar using sterile cork-borer, filled with serially increasing concentrations (100 to $1000 \mu \mathrm{g} / \mathrm{ml}$ ) of the Fluconazole, and $O$. sanctum oil and refrigerated for 15 minutes for pre-diffusion. After the pre-diffusion step, the plates were incubated overnight at $30^{\circ} \mathrm{C}$. Fluconazole test solutions were prepared by crushing the tablet using a mortar and pestle using dimethyl sulfoxide (DMSO). The lowest concentration showing a zone of inhibition (ZI) > $15 \mathrm{~mm}$ diameter was taken as the MIC for both antifungal agents.

The MICs of the antifungal agents were also investigated using standard microtitre plate assay. Flat bottomed 96-well microtitre plates (Tarsons $\mathrm{TM}$, India) were filled with $100 \mu$ of serially diluted solutions of the antifungal agents (ranging from 2000 to $200 \mu \mathrm{g} / \mu \mathrm{l}$ ). To each well, $100 \mu \mathrm{l}$ of freshly grown candida cells $\left(1 \times 10^{5}\right.$ cells $/ \mathrm{ml}$ ) were added. The plates were incubated at $30^{\circ} \mathrm{C}$ overnight and OD600 was measured using a double-beam UV-V is spectrophotometer (Shimadzu, Japan). As the incorporation of the antifungal agents did not alter the OD600 of the solution significantly, $200 \mu \mathrm{l}$ of sterile YMB broth served as the negative control.

Evaluation of fungal culture viability in presence of antifungal agents

Fungal cultures were grown overnight in a sterile YMB medium in presence of MIC values of Fluconazole and $O$. sanctum oil. Further microscopic observations were carried out up to 14 days to check the viability of fungal cells with time. The initial concentration of cells was adjusted to $1 \times 10^{5}$ cells $/ \mathrm{ml}$ on a Neubauer chamber: $1 / 400 \mathrm{~mm}^{2}$, depth $0.1 \mathrm{~mm}$ (Axiva - Counting Chamber Brightline Touff, Delhi, India). 


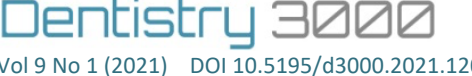

\section{Preparation of denture disk} specimens

Soft liner denture disks of Mollosil, with silicone based permanent chair side soft liner (Detax GmbH \& Co. KG, Carl-Zeiss-Str.4, Germany) were prepared as per manufacturer's instructions in a laminar flow (Microfilt India Pvt. Ltd.). The base paste and catalyst paste were mixed in 1:1 $\mathrm{w} / \mathrm{w}$ ratio on a sterile ceramic (Figure 2). Denture disc specimens of diameter $=12 \mathrm{~mm}$, and thickness $=2$ $\mathrm{mm}$ were prepared for antifungal assay. A stainless steel mould was used to prepare denture discs specimens of diameter $=20 \mathrm{~mm}$, and thickness $=5 \mathrm{~mm}$ were also prepared for the assessment of physical properties.

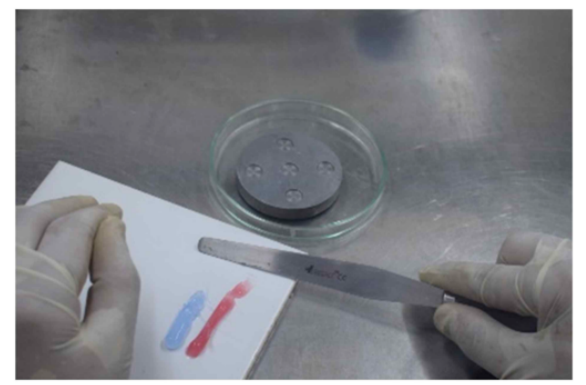

Figure 2. Preparation of denture soft liner disk specimens using stainless steel mold.

The antifungals to be incorporated were also pre-weighed and added according to their MIC values to the pastes. The material was homogenously mixed using a stainless-steel using spatula for 30 seconds and then gently placed over the mould which was further secured between two thick glass tiles, under constant pressure to ensure the uniformity without any voids. The specimens were allowed to set for 8 10 minutes at room temperature until the mix was plastic and easy to retrieve. Any specimens with voids or irregular surfaces were discarded. The excess portion was trimmed off carefully using a fine blade scissor. The specimens were then coated with lustrol gloss varnish and were allowed to dry for 5 minutes and stored further in a sterile petri dish. The procedure was repeated for both test compounds using all concentrations. For the control group, no antifungal agent was incorporated. These specimens were stored in a sterile container having $10 \mathrm{~mL}$ of artificial saliva.

Determination of physical properties (surface roughness and hardness) of the soft liner

Surface roughness was measured using a surface roughness tester (Mitutoyo South Asia Pvt. Ltd) calibrated with a $0.8 \mathrm{~mm}$ cut-off length and speed of $0.5 \mathrm{~mm} / \mathrm{s}$. The hardness was measured on one side of specimen using a Shore $A$ durometer (Kori Seiki, Japan). A constant load of $10 \mathrm{~N} / \mathrm{s}$ was applied, and the results were obtained from 0 to 100 Shore $A$ units. A mean of five readings was taken, from different sites of the sample for both the properties. Both physical properties were measured at a regular interval of 24 hours (up to two weeks) [25].
Demonstrating the effect of antifungal agents on C. albicans using Scanning Electron Microscopy

C. albicans was grown in YMB for an overnight to achieve a mid-log phase to reach a cell count of $1 \times 10^{5}$ cells. After growth; the cells of $C$. albicans were centrifuged $(10,000 \mathrm{rpm}$ for 15 minutes at $4^{\circ} \mathrm{C}$ ) and the supernatant was discarded. Further, cell pellet was washed with saline $(0.85 \% \mathrm{NaCl})$ for one to two minutes. The pellet was made up to $1 \mathrm{ml}$ with the saline and was labelled as a stock. Around $1 \mu \mathrm{L}$ from the stock was then diluted to $10^{3}$ times and the cells were counted using Neubauer chamber underneath a $1 \mathrm{~mm}$ thick coverslip under $40 \mathrm{x}$ magnification. From this, the amount of stock needed to get $1 \times 10^{5}$ cells was calculated. The cells grown in mid log phase ( $1 \times 10^{5}$ cells) were treated with their respective MICs of both antifungal agents. The tubes were further incubated at $30^{\circ} \mathrm{C}$ for four hours at $150 \mathrm{rpm}$. The cells were collected by centrifugation at 10,000 rpm for 15 minutes at $4^{\circ} \mathrm{C}$ and the pellet was then washed thrice with $0.1 \mathrm{M}$ phosphate buffer saline (PBS) at $\mathrm{pH}$ 7.4. The cell pellet was then fixed with $2.5 \%$ glutaraldehyde at $4^{\circ} \mathrm{C}$ for four hours. It was then rinsed twice with PBS. After the rinsing step, the pellets were dehydrated in ethanol series ranging from $10-$ $100 \%$, for 15 minutes per step. At the end of this stage, water content from the cell was completely replaced with ethanol and this was used further for SEM studies. Around $2 \mu \mathrm{l}$ of this was spread uniformly on a 
entistrப $3 \square \square \square$

Vol 9 No 1 (2021) DOI 10.5195/d3000.2021.120

clean, grease free glass cube $(1 \times 1$ $\mathrm{mm}$ ) and allowed to air dry completely in a laminar air flow to observe it using SEM facility.

\section{Statistical analysis of data}

All experiments were performed in triplicates. The numerical readings for all three parameters were subjected to statistical analysis. The data obtained on continuous variables were presented as Mean and Standard deviation ( \pm SD). The intergroup statistical comparison of continuous variables was done using analysis of variance with Bonferroni's correction for multiple group comparisons. The intra-group statistical comparisons were done using repeated measures analysis of variance (RMANOVA). The $p$-values < 0.05 were considered as statistically significant. The entire data were statistically analyzed using Statistical Package for Social Sciences (SPSS version 21.0, IBM Corporation, USA) for MS Windows.

\section{Results}

In the present study, a biofilm forming strain C. albicans (ATCC 10231) was selected for antifungal assays to mimic the characteristics of oral microflora. C. albicans showed atypical colony morphology on YMA plate. Candida cells stained with lactophenol cotton blue in absence and presence of antifungal agents are shown in Figure $\mathbf{3 a}, \mathbf{3 b}$ and $\mathbf{3 c}$.

Antifungal activity performed through agar well plate assay manifested the potency of Fluconazole and $O$.

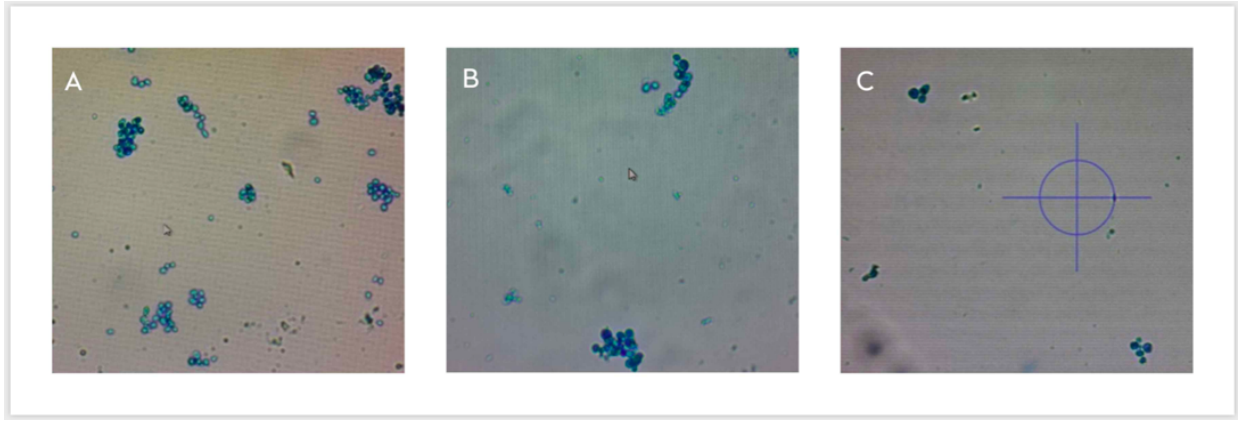

Figure 3. A) Microscopic image of C. albicans in absence (Control) of antifungal agents, B) Microscopic image of C. albicans in presence (Test) of Fluconazole (MIC $=600 \mu \mathrm{g} / \mathrm{ml}), \mathrm{C}$ ) Microscopic image of $C$. albicans in presence (Test) of $O$. sanctum oil (MIC $=400 \mu \mathrm{g} / \mathrm{ml}$ ).
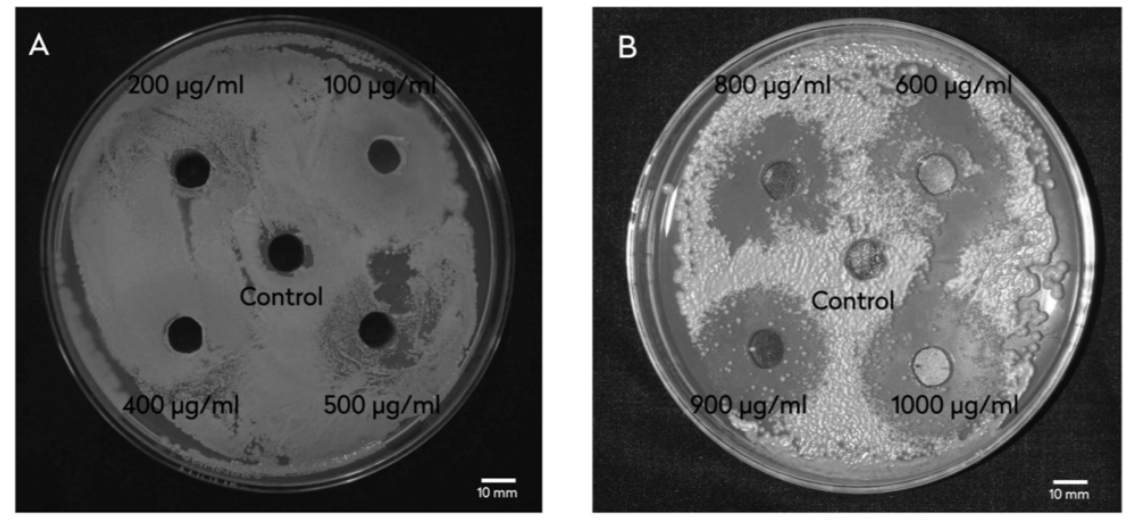

Figure 4. Antifungal activity of Fluconazole against $\mathrm{C}$. albicans grown on YMA agar plate in well diffusion assay performed with its different concentrations (100 to $1000 \mu \mathrm{g} / \mathrm{ml}$ ). Fluconazole exhibiting the zone of inhibition against $\mathrm{C}$. albicans as compared to negative control (Control well: Centre one filled with Dimethyl sulfoxide)

sanctum oil at MIC of 600 and 400 $\mu \mathrm{g} / \mathrm{ml}$ respectively. Figure 4

represents the increased diameter of $\mathrm{ZI}$ around the well with increased concentrations of Fluconazole against C. albicans culture, proving its concentration dependent antifungal activity. A 96 well plate micro-titre assay also supported the same MIC values as reflected through well plate assay for both antifungal agents.

Cell viability assay confirmed that the negative control, where the cell count was much higher $\left(26 \times 10^{5} / \mathrm{ml}\right)$ as compared to the candida cells treated with both antifungal agents individually (Fluconazole : $6 \times 10^{5} / \mathrm{ml}$ and $O$. sanctum oil : $4 \times 10^{5} / \mathrm{ml}$ ). Such a drastic decrease in the cell count indicates a powerful antifungal effect of both agents and proving their significance in control of candida culture. Viable cell counts in the presence of antifungal agents showed significant reduction ( $p=0.001)$ in cell count due to antifungal activity of test samples (having Fluconazole and $O$. sanctum oil) as compared to the 

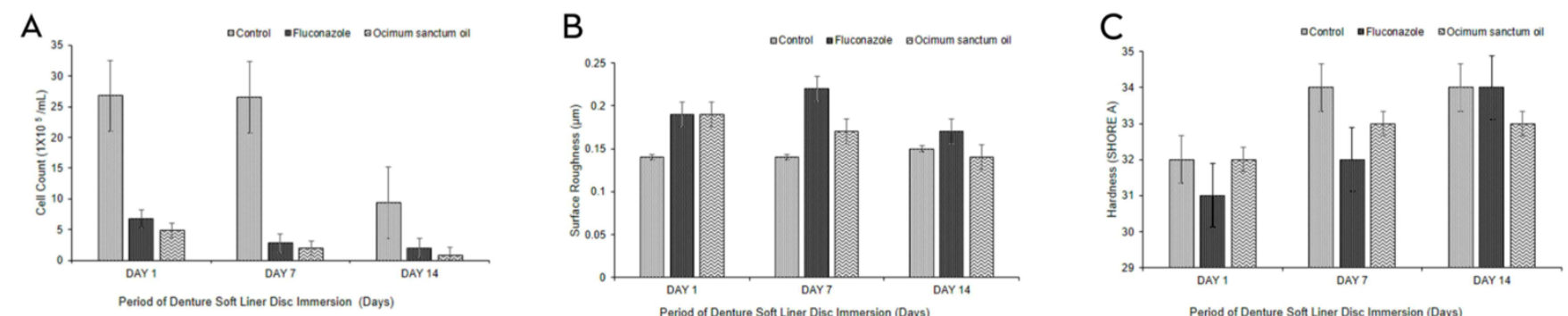

Period of Denture Soft Liner Disc Immersion (Days) Period of Denture Soft Liner Disc Immersion (Days)

Figure 5. A) Graphical representation for cell count of C. albicans treated with (test) and without (control) antifungal agents, B) Graphical representation for the surface roughness of denture specimens incorporated with (test) and without (control) antifungal agents, C) Graphical representation for Shore A hardness of denture specimens incorporated with (test) and without (control) antifungal agents.

control (no antifungal agent) over 24 hours, 7 days and 14 days (Figure 5a). These MIC values were also used to prepare denture disc soft - liner specimens for further studies. Cell viability of the antifungal agents treated culture certainly affected the growth of $C$. albicans as compared to control.

Denture soft liner disc specimens incorporated with antifungal agents should not significantly alter their physical property which was clearly reflected in the present studies. The surface roughness (Figure $\mathbf{5 b}$ ) and hardness (Figure $\mathbf{5 c}$ ) of the denture disc specimens incorporated with antifungal agents at their respective MIC over 24 hours, 7 days and 14 days shows no significant alterations. $(p=0.99)$

\section{SEM images of $C$.}

albicans illustrated significant changes in the morphology of candida cells in presence Fluconazole and $O$. sanctum oil under different magnification (Refer Figure 6). Figure $6 \mathbf{a}$ to $\mathbf{6 c}$ represents the SEM images untreated or the control cells

(without antifungal treatment) having its natural smooth, oval-shape and polar budding type with blastoconidia. However, treatment of candida cells with antifungal agents (at their respective $\mathrm{MIC}$ ) showed complete damaged cell surface as shown in Figure $\mathbf{6 d}$ to $\mathbf{6 f}$ for Fluconazole and Figure $\mathbf{6 g}$ to $6 \mathbf{i}$ for $O$. sanctum oil. Thus, SEM studies also supported the outcome of the
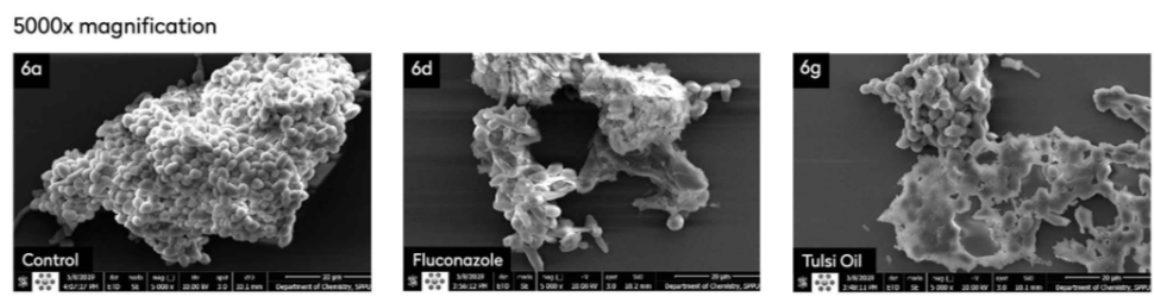

$10000 x$ magnification
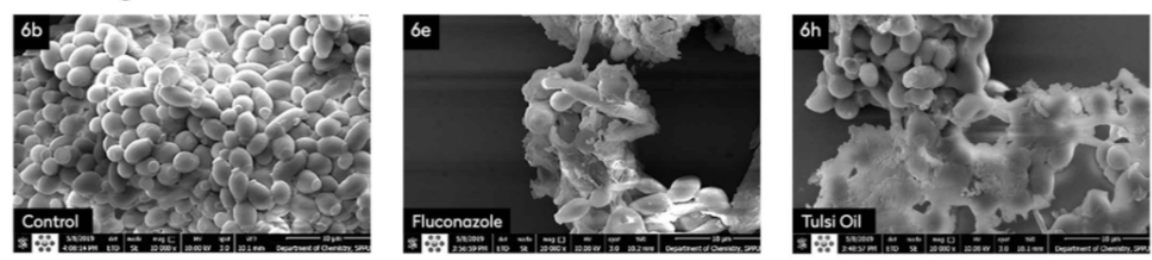

$30,000 x$ magnification
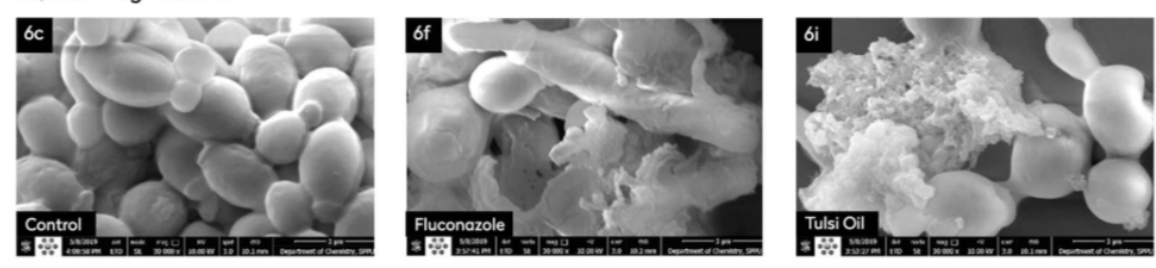

Figure 6. Scanning electron microscopic images of Cell surface morphology of C. albicans in the presence (test) and absence (control) of antifungal agents at their MIC values under different magnification levels. A) $(5000 x)$ B) (10000x) C) (30000x): Control without any antifungal agents showing normal cell morphology while, D) (5000x), E) (10000x) and F) (30000x): In the presence of Fluconazole $(600 \mu \mathrm{g} / \mathrm{ml}$ ) and G) (5000x), H) (10000x) and I) (30000x): In the presence of $O$. sanctum oil $(400 \mu \mathrm{g} / \mathrm{ml})$ clearly show ruptured cells. 
experiments from the agar well plate and microtitre assay proving the antifungal activity of both agents.

\section{Discussion}

Temporary soft denture liners are alike to tissue conditioners; that improves the health of inflamed, hypertrophic, hyperaemic, and traumatized denture-bearing tissues [14]. They provide cushioning effect under dentures by distributing the functional stresses, thereby can especially be beneficial in reducing the pain arising from the severely resorbed, sharp and thin residual crests [25]. During this process, plaque accumulated to the tissue surface, can cause microbial adhesion to the soft liner [14]. C. albicans is an established pathogen in denture stomatitis, especially in geriatric patients with poor oral hygiene, and in patients with physical or mental disabilities.

Budtz-Jorgensen et al and Koopmans et al showed that the percentage of yeasts was statistical significantly higher in the denture related stomatitis (DRS) group [26,27]. Complete denture wearers have shown higher prevalence of candida infections, due to microbial adherence on denture bases and liners; leading to varying degrees of denture stomatitis. The surface properties of denture liners, salivary composition, low $\mathrm{pH}$, and diets rich in carbohydrates accelerate the colonization and adhesion of $C$. albicans, causing exponential growth that possibly encourage denture stomatitis. The initial adhesion of $C$. albicans depends on the micro porosities of denture base material and lack of oral hygiene, which encourages the formation of a sessile community and biofilm in the oral cavity [14]. In the present study, biofilm forming C. albicans was selected for fungal assays to mimic the characteristics of oral microflora. Evaluation of this strain using a trinocular microscope showed actively budding yeast cells when cultured overnight in YMB.

Fluconazole and $O$. sanctum oil are known for their antifungal activity [28]. Similar observations were noted in the current study. Noteworthy reduction in cell viability of candida in artificial saliva proposes efficacy of antifungal against candida cells without affecting the physical properties of the denture material. This reflection agrees to Bates et al and Bueno et al $[24,28]$. The mixing of the base materials with antifungal agents may result to covalent binding of the antifungal agents that fetches their controlled discharge over prolong periods of time in the oral cavity or on site colonized by candida cell on the denture surface. The observation of the antifungal assay shows that there was a gradual reduction in the growth of the organism over the three intervals of 24 hours, 7 and 14 days. Since denture stomatitis is a multi-factorial condition, the treatment is complex and host-dependent [29].
Antifungal agents are considered as a potent and safe medications for both topical and systemic therapies for mucosal lesions [1,2]. Although these are considered to be safe and effective topically, prolonged systemic use may cause renal toxicity or hepatotoxicity [11]. Using topical antifungal agents are effective on the fungal pathogens that invade superficial tissues. However, their usage may be associated with a few undesirable effects for example, objectionable taste and necessity of frequent applications [5]. Due to their shortcomings, the concept of incorporating antifungal agents in denture liners was advocated. The idea of incorporating antifungal agents into denture liners was introduced by Douglas and Walker, since, a plenty of research has been conducted to improvise the efficacy of tissue conditioners using a variety of antifungal medicaments [30]. Thus, addition of fungicidal compounds directly to the tissue conditioners or denture liners has numerous advantages: extremely low-cost and successful technique. This method can be readily employed for those patients at high risk: patients with xerostomia and those with a history of denture stomatitis [31]. The antifungal effects of fluconazole and O. sanctum oil incorporated in denture soft liners have not been compared by in existing literature.

The antimicrobial susceptibility and efficacies of any drug are analysed by determining its MIC. The viability of topical antimicrobials is lowered than 
its therapeutic concentration due to the cleaning action of the musculature, the diluent effect of saliva, and the microbial colonization in complex biofilms. Therefore, candida cells were exposed to a limited concentration of the antifungal $[32,33]$. It may be assumed that the release of antimicrobial agents incorporated in denture materials after temporary relining of contaminated acrylic surfaces is uniform and steady in infected sites, maintaining an effective concentration, although it is still lower than the initial [5]. In this study, MIC were determined where the diameter of ZI measured for different concentrations of Fluconazole and $O$. sanctum oil and also confirmed by using a 96 well plate micro-titre assay. The MIC for fluconazole for $C$. albicans ATCC 10231 was 600 mg/ml and that for $O$. sanctum was 400 $\mu \mathrm{g} / \mathrm{ml}$. These results are similar to that achieved by Balakumar et al who assessed the activity of $O$. sanctum on clinically isolated dermatophytic fungi. They found the MIC values of the oil in the range of 125 to 400 $\mu \mathrm{g} / \mathrm{ml}$ [34].

Surfaces with greater roughness usually exhibit higher yeast count; owing to higher irregularities and microporosities. The microscopic surface peaks and valleys protect the microbes from shear forces, even during denture cleaning, allowing the entrapped microbial cells to attach irreversibly to a surface [35]. In the current study, incorporation of the antifungal agents in the soft liner material during preparation of the soft liner discs did not result in any significant increase in the surface roughness or Shore A hardness of the material $(p<0.05)$ even after 14 days of incubation $(p<0.05)$ when compared with the control. Higher mean values of surface roughness for auto-polymerizing soft lining materials ( 2.8 to $4.2 \mu \mathrm{m}$ ) and tissue conditioners (1.3 to $7.9 \mu \mathrm{m}$ ) were previously described by Kang et al and by Bueno et al (5.04 to $6.00 \mu \mathrm{m}$ ) $[24,36]$. These variations of roughness values may be ascribed to differences among the used experimental conditions and also the chemical condition of test materials.

Furthermore, in In Vivo conditions, the variations may occur due to thermal changes, $\mathrm{pH}$ variations and deformation by occlusal load [24]. There are no limitations for clinically acceptable values for the Shore $A$ hardness of temporary soft lining materials. However, a variation from 13 to 49 Shore A units in 24 hours is regarded as acceptable for clinical use of these materials [37]. The results achieved in the present study are in this range for all test groups. A hardness of $20-25$ units without any change during the life cycle of a resilient material is considered clinically suitable, as reported by Bueno et al, Gonzalez et al and Yilmaz et al who found higher Shore $A$ hardness values (60-78 units) for three temporary soft lining materials $[24,38,39]$.

The scanning electron microscopy observations presented clearly confirm significant fungicidal action exerted by fluconazole and $O$. sanctum oil. The surface alterations are most probably due to a change in cell permeability. As for the cells treated with the fungicidal dose, some have a completely smooth surface fully comparable to those seen in the controls, though the surfaces of most cells were partly covered with vesicles. Vesicular material possibly originates from the cytoplasmic components of the broken and damaged cells [40]. Thus, indicating the efficacy of the two test antifungals used in the present study.

Although significant conclusions have been drawn from this study, it is necessary to clinically correlate the same under In Vivo, conditions to promote the use of these anti-fungal medicaments in day-to-day use for management of denture stomatitis. In addition, the In Vitro specimens are usually smoother and have standardized surfaces, which increases the effectiveness of the tests of antifungal agents; In Vivo, denture liners lose their plasticizers, becoming hardened and rough.

\section{Conclusion}

In conclusion antifungal agents Fluconazole and $O$. sanctum oil tested in the current study showed comparatively greater reduction in cell count of $C$. albicans at the concentration of 600 and $400 \mu \mathrm{g} / \mathrm{ml}$ respectively. The surface roughness and hardness of soft denture liners remains more or less unaltered after incorporation of antifungal agents. 
The efficacy of effect of antifungal agents demonstrated destruction of C. albicans and was evident through SEM studies. Work demonstrated through this approach allows the prolonged drug release in the oral cavity which simultaneously treats the injured denture bearing tissues and reduce not only candida infection as well as their colonization. These studies are significant and have promising medicinal and therapeutic perspectives.

\section{Acknowledgements}

We express special gratitude to Rashtriya Uchchattar Shiksha Abhiyan - RUSA-CBS-TH- 3.2 for financial support and Prof. Gajanan Zore, Swami Ramanand Teerth Marathawad University, Nanded for providing the necessary Candia strains.

\section{Conflicts of interest}

The authors deny any conflicts of interest in regards to the current study.

\section{References}

1. Comparative evaluation of two antifungal agents incorporated in auto polymerising denture base resin, heat polymerising denture base resin and permanent silicone soft liner-An in vitro study. Chincholikar S, Sridevi J, Kalavathy N, Singh S, Kapoor A, Saumya S. J Clin Diag Res 2019;13. DOI :

10.7860/JCDR/2019/37889.12520

2. Effect of incorporation of antifungal agents on the ultimate tensile strength of temporary soft denture liners. Neppelenbroek KH, Lima JF, Hotta J, Galitesi LL, Almeida AL, Urban VM. J Prosthodont 2018;27:177-181.

DOI: 10.1111/jopr.12660

3. Biofilm production by Candida species and inadequate antifungal therapy as predictors of mortality for patients with candidemia. Tumbarello M, Posteraro B, Trecarichi EM, Fiori B, Rossi M, Porta R, de Gaetano Donati K, La Sorda M, Spanu T, Fadda G, Cauda R. J Clin Microbiol 2007;45:1843-1850.

DOI: 10.1128/JCM.00131-07

4. Predisposing factors, prevention, diagnosis and alternative treatment. Martins N, Ferreira ICFR, Barros L, Silva S, Henriques M. Candidiasis: Mycopathologia 2014;177:223-240. DOI: 10.1007/s11046-014-9749-1

5. Role of antifungal medicaments added to tissue conditioners: a systematic review. Iqbal Z, Zafar MS. J Prosthodont Res 2016;60:231-239. DOI: 10.1016/j.jpor.2016.03.006

6. Denture plaque and adherence of Candida albicans to denture-base materials in vivo and in vitro. Radford D, Challacombe SJ, Walter JD. Crit Rev Oral Biol Med 1999;10:99-116.

DOI:

10.1177/10454411990100010501

7. A comparative efficacy of Nystatin and Fluconazole incorporated into tissue conditioner as drug delivery method for Denture stomatitis. Kumar N, Kumari A, Priyadarshi V, Kumar A, Prasad RS, Kumar B. J Adv Med Dent Scie Res 2020;8(1):159-62. DOI: 10.4103/ccd.ccd_542_17

8. Evaluation of the physical and antifungal effects of chlorhexidine diacetate incorporated into polymethyl methacrylate. Maluf $\mathrm{CV}$, Peroni LV, Menezes LR, Coutinho W, Lourenço EJ, Telles DD. J Appl Oral Sci 2020;28.

DOI: 10.1590/1678-7757-2019-0039

\section{Structural insights into} conformation of amphiphilic quaternary ammonium chitosans to control fungicidal and anti-biofilm functions. Jung J, Bae Y, Cho YK, Ren $X$, Sun Y. Carbohydr polym 2020;228:115391.

DOI: 10.1016/j.carbpol.2019.115391

10. Effect of incorporation of silver nanoparticles on the tensile bond strength of a long term soft denture liner. Habibzadeh S, Omidvaran A, Eskandarion S, Shamshiri AR. Eur J Dent 2020;14(2):268. DOI: $10.1055 / \mathrm{s}-0040-1709923$

11. Clinical pharmacology of fluconazole. Dudley MN.

Pharmacotherapy: J Human Pharmacology and Drug Therapy 1990;10:141-145 https://doi.org/10.1002/j.18759114.1990.tb02599.x

12. Fluorinated vs. zwitterionicpolymer grafted surfaces for adhesion prevention of the fungal pathogen Candida albicans. Masotti E, Poma N, Guazzelli E, Fiaschi I, Glisenti A, Vivaldi F, Bonini A, Francesco FD, Tavanti A, Galli G, Martinelli E. Polymers 2020;12(2):398. DOI: $10.3390 /$ polym 12020398

13. Evaluation of the properties of a tissue conditioner containing origanum oil as an antifungal additive. Srivatstava A, Ginjupalli K, Perampalli NU, Bhat N, Ballal M, J Prosthet Dent 2013;110:313-319. 
DOI: 10.1016/S0022-3913(13)60381-9

14. Comparative evaluation of antifungal activity of melaleuca oil and fluconazole when incorporated in tissue conditioner: an in vitro study. Sharma S, Hegde V. J Prosthodont 2014;23:367-373.

DOI: $10.1111 /$ jopr.12117

15. Effect of incorporating seed oils on the antifungal property, surface roughness, wettability, weight change, and glucose sorption of a soft liner. Muttagi S, Subramanya JK. J Prosthet Dent 2017;117:178-185. DOI: 10.1016/j.prosdent.2016.05.010

16. Nature cures- An alternative herbal formulation as a denture cleanser. Sushma R, Sathe TT, Farias A, Sanyal PK, Kiran S. Ann Afr Med 2017;16:6-12.

DOI: 10.4103/aam.aam_43_16

17. Randomized controlled clinical trial of Ocimum sanctum and chlorhexidine mouthwash on dental plaque and gingival inflammation. Gupta D, Bhaskar DJ, Gupta RK, Karim $B$, Jain A, Singh R, Karim WA. J Ayurveda Integr Med 2014;5:109116.

DOI: $10.4103 / 0975-9476.131727$

18. In vitro activity of eugenol, an active component from Ocimum sanctum, against multiresistant and susceptible strains of Neisseria gonorrhoeae. Shokeen P, Bala M, Singh $\mathrm{M}$, Tandon V. Int J Antimicrob Agents 2008;32:174-179.

DOI:

10.1016/j.ijantimicag.2008.03.018

19. An in vitro analysis of a sustained release system for the treatment of denture stomatitis. Schneid TR. Special Care in Dentistry
1992;12(6):245-50.

DOI: $10.1111 /$ j.1754-

4505.1992.tb00458.x

20. Effect of 3 types of antifungal agents on hardness of 2 different commercially available tissue conditioners: An in vitro study. Jadhav V, Shetty MM, Kalavathy N, Kumar R. SRM J Res in Dental Sci 2013;1;4(4):150.

DOI: $10.4103 / 0976-433 X .125590$

21. Effect of the addition of antimicrobial agents on Shore $A$ hardness and roughness of soft lining materials. Urban VM, Lima TF, Bueno MG, Giannini M, Arioli Filho JN, de Almeida AL, Neppelenbroek KH. J Prosthodont 2015;24(3):207-214. DOI: $10.1111 /$ jopr.12205

22. Effect of the association of nystatin with a tissue conditioner on its ultimate tensile strength. Urban VM, De Souza RF, Galvao Arrais CA, Borsato KT, Vaz LG. J Prosthodont 2006;15:295-299.

DOI: $10.1111 /$ j.1532-

849X.2006.00130.x

23. Superficial distribution and identification of antifungal/antimicrobial agents on a modified tissue conditioner by SEMEDS microanalysis: a preliminary study. Urban VM, Seó RS, Giannini M, Arrais CA. J Prosthodont: Implant, Esthet Reconst Dent 2009;18(7):603610.

DOI: $10.1111 /$ j.1532-

849X.2009.00479.x

24. Surface properties of temporary soft liners modified by minimum inhibitory concentrations of antifungals. Bueno MG, Sousa EJ, Hotta J, Porto VC, Urban VM, Neppelenbroek KH. Brazilian Dental J
2017;28:158-164.

DOI: 10.1590/0103-6440201701266

25. Candida albicans adherence and proliferation on the surface of denture base materials. Koch C, Bürgers R, Hahnel S. Gerodontology 2013;30:309-313.

DOI: 10.1111/ger.12056

26. An epidemiologic study of yeasts in elderly denture wearers. BudtzJorgensen E, Stenderup A, Grabowski M. Community Dent Oral Epidemiol 1975;3:115-119.

DOI: $10.1111 /$ j.1600-

0528.1975.tb00291.x

27. Bacterial involvement in dentureinduced stomatitis. Koopmans A, Kippuw N, Graaff J. J Dent Res 1988;67:1246-1250.

DOI:

\subsection{7/00220345880670091901}

28. Diminished antimicrobial peptide and antifungal antibiotic activities against Candida albicans in denture adhesive. Bates AM, Garaicoa JL, Fischer $\mathrm{CL}$, Brogden KA. Antibiot 2017;6:6.

DOI: $10.3390 /$ antibiotics6010006

29. Candida-associated denture stomatitis. Aetiology and management: a review. Part 3. Treatment of oral candidosis. Webb BC, Thomas CJ, Willcox MD, Harty DW, Knox KW. Australian dental journal. 1998;43:244-249. DOI: $10.1111 /$ j.18347819.1998.tb00152.x

30. Nystatin in denture liners- an alternative treatment of denture stomatitis. Douglas CJ, Walker DM. Brit Dent J 1973;135:55-58. DOI: 10.1038/sj.bdj.4803045 
31. Effect of triazine derivative added to denture materials on a microcosm biofilm model. De Moraes AP, Barwaldt CK, Nunes TZ, Sarkis-Onofre $\mathrm{R}$, Ogliari FA, Boscato N, Pereira-Cenci T. J Biomed Mater Res B Appl Biomater 2012;100:1328-1333. DOI: 10.1002/jbm.b.32699

32. Microwave disinfection of dentures for the treatment of oral candidiasis. Banting DW, Hill SA. Special Care in Dentist 2001;21:4-8. DOI: $10.1111 /$ j.17544505.2001.tb00216.x

33. Adhesion of oral Candida albicans isolates to denture acrylic following limited exposure to antifungal agents. Ellepola AN, Samaranayake LP. Arch Oral Biol 1998;43:999-1007. DOI: 10.1016/s0003-9969(98)00075-2

\section{Antifungal activity of Ocimum} sanctum Linn. (Lamiaceae) on clinically isolated dermatophytic fungi. Balakumar S, Rajan S, Thirunalasundari T, Jeeva S. Asian Pacific J Tropical Med 2011;4:654657.

DOI: 10.1016/s1995-7645(11)60166-1

35. Development of Candidaassociated denture stomatitis: new insights. Pereira-Cenci T, Del Bel Cury AA, Crielaard W, Ten Cate JM. J Appl Oral Science 2008;6:86-94.

DOI: $10.1590 / S 1678-$

77572008000200002

36. Influence of surface characteristics on the adhesion of Candida albicans to various denture lining materials. Kang SH, Lee HJ, Hong SH, Kim KH, Kwon TY. Acta Odontologica Scandinavica.

2013;1;71(1):241-248.

DOI: $10.3109 / 00016357.2012 .671360$
37. Prosthetics applications of polymers. Craig RG. 10th ed. St. Louis: Mosby 1997;551.

38. Use of tissue conditioners and resilient liners. Gonzalez JB. Dent Clin North Am 1977;21:249-259.

39. Effects of different disinfectants on physical properties of four temporary soft denture-liner materials. Yilmaz $\mathrm{H}$, Aydin $\mathrm{C}$, Turhan Bal B, Ocak F. Quintessence Int 2004;35:826-834.

40. The effects of miconazole on the ultastructure of Candida albicans. Sonja De Nollin, Borgersand M, VanBelle H. Roc Roy Soc Med 1977; Supplement 4. 